\title{
Primary extraskeletal Ewing's sarcoma/primitive neuroectodermal tumour of breast
}

\author{
S M Ikhwan, ${ }^{1}$ V K T Kenneth, ${ }^{1}$ A Seoparjoo, ${ }^{2}$ A A M Zin ${ }^{2}$
}

${ }^{1}$ Department of General Surgery, Universiti Sains Malaysia, Kota Bharu, Kelantan, Malaysia ${ }^{2}$ Department of Pathology, Universiti Sains Malaysia, KotaBharu, Kelantan, Malaysia

\section{Correspondence to} Dr S M Ikhwan,

ikhwansani@yahoo.com.my
To cite: Ikhwan SM, Kenneth VKT, Seoparjoo A, et al. BMJ Case Rep Published online: [please include Day Month Year] doi:10.1136/bcr-2013009584

\section{SUMMARY}

Primary primitive neuroectodermal tumour (PNET) and extraskeletal Ewing's sarcoma belongs to the Ewing's family of tumours. Primary tumours arising from breast are very rare. There are only a few case reports published on primary extraskeletal Ewing's sarcoma and PNET arising from breast. We present an extremely rare case of an inoperable primary Ewing's sarcoma arising from left breast with contralateral breast, lymphatic and lung metastasis.

\section{BACKGROUND}

As far as the author is concerned, there are not many cases reported worldwide about this rare pathological diagnosis of a breast cancer. This will lead to further discussion towards management options to the disease; either one should follow the usual algorithm of managing breast carcinoma or adopt a different management approach.

\section{CASE PRESENTATION}

A 33-year-old nulliparous woman presented with 1 year history of left breast lump, initially started as a small discrete painless lump, gradually enlarging to occupy the entire left breast (figure 1). She also noticed hard lumps developing over the right axillary region over 2 months prior with slight swelling of the right breast (figure 2). She had loss of weight of approximately $10 \mathrm{~kg}$ in the last 3 months with lethargy and backache. On examination, the entire left breast was erythematous, indurated and fixed. There was presence of ulceration over the skin surface with contact bleeding and pus discharge. The contralateral breast had peau de orange skin appearance with multiple fixed axillary lumps. She was anaemic requiring blood

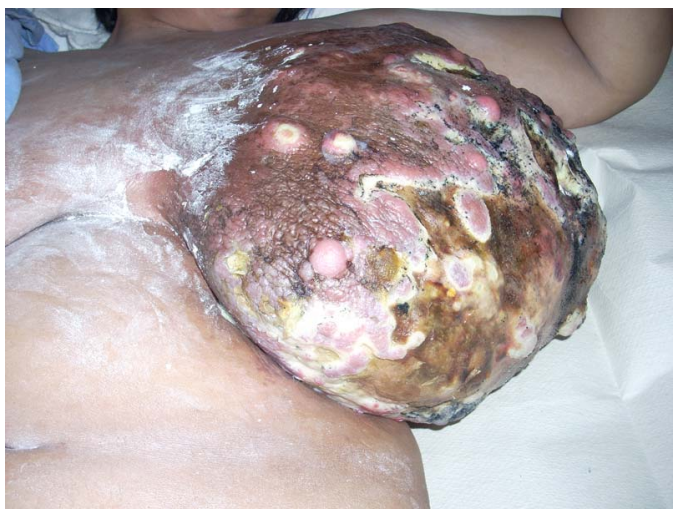

Figure 1 The mass occupied the whole left breast. transfusion. There were no other lesions arising from the trunk or limbs.

\section{INVESTIGATIONS}

CT scan of thorax, abdomen and pelvis revealed left breast tumour which was lobulated and heterogeneously enhancing, with poor plane of demarcation between the tumour, skin and anterior chest wall muscles. Multiple large mediastinal and bilateral axillary lymphadenopathies were seen. Bilateral multiple lung nodules were present with thickening of pleura. No liver lesion seen. No other bone or suspicious soft tissue lesions were seen on the axial skeleton and trunk (figure 3).

Core biopsy sample, using trucut needle, was taken from the left breast. Histopathological interpretation from the breast lesion biopsy was reported as presence of malignant small round blue cells, arranged in solid sheet with area of necrosis. Cells were mildly pleomorphic, moderate eosinophilic cytoplasm, round nuclei and small inconspicuous nucleoli. There were clear intracytoplasmic vacuoles which contained glycogen. Number of mitosis was 6 in 10 high power field microscopy. Special staining preformed showed positive to PAS and PD stain was removed by diastase. Immunohistochemical staining was focally positive to $\mathrm{CK} \mathrm{AE} 3$ and AE1, positive to vimentin, CD99, synaptophysin and chromogranin A (figure 4).

\section{DIFFERENTIAL DIAGNOSIS}

As there were no other tumours arising from the trunk or limbs, she was assessed to have a primary test for Ewing's sarcoma/primitive neuroectodermal

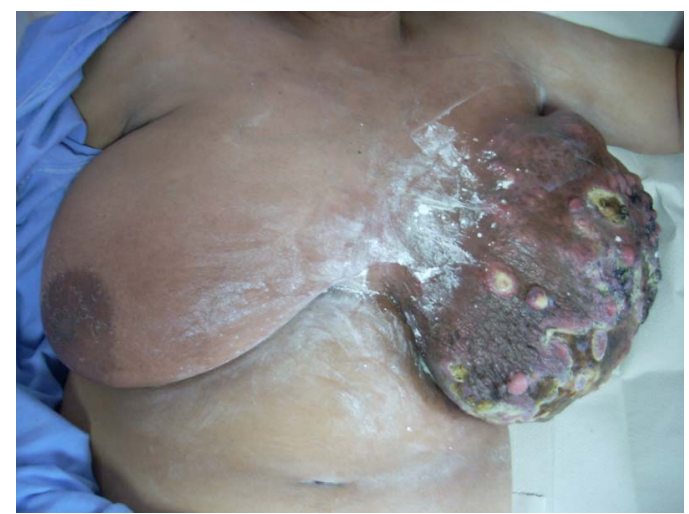

Figure 2 The right breast grossly appeared normal compared with the distorted architecture of the left breast. 


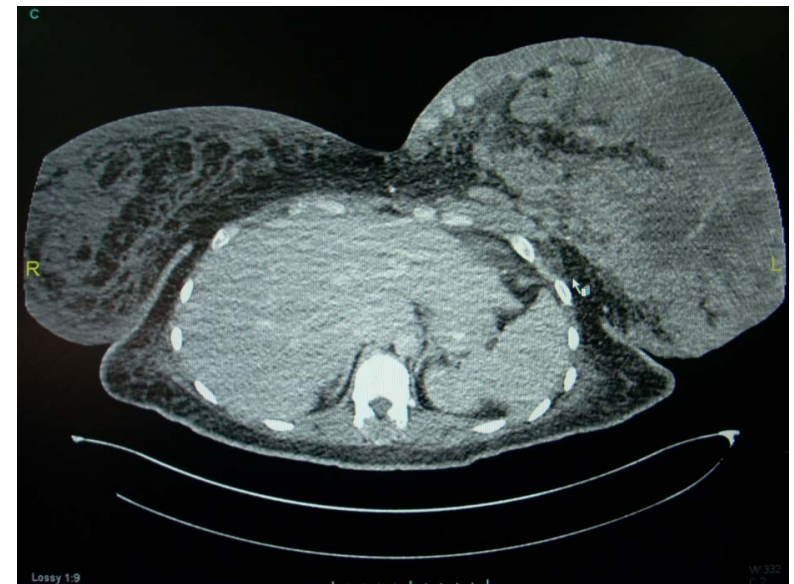

Figure 3 Appearance of the left breast lesion on CT scan.

tumour (PNET) of left breast with contralateral breast, lymphatic and lung metastasis.

\section{TREATMENT}

In view of metastatic disease on presentation with large locally invasive tumour bilaterally, she was subjected for chemotherapy using vincristine, adriamycin and cyclophosphamide (VAC) regime as first line of treatment, with the view of offering toilet mastectomy for local control after down-sizing the tumour.

\section{OUTCOME AND FOLLOW-UP}

Unfortunately, this woman succumbed to her illness after receiving three cycles of chemotherapy.

\section{DISCUSSION}

In 1975, Angervall and Enzinger first reported extraskeletal Ewing's sarcoma occurring predominantly in adolescents and young adults between the age 10 and 30 years. It follows an aggressive course, with a high recurrence rate. The commonest sites are chest wall, lower extremities and paravertebral region followed by upper extremities, hip and pelvis. ${ }^{1}$ From these tumour sites metastasis have been reported to breast. ${ }^{1}{ }^{2}$ According to Baldini et al Ewing's sarcoma and PNET are histologically 'small round blue cell tumours'. The majority of cases share the cytogenetic translocation $\mathrm{t}(11 ; 22)$ (q24;q12), with occasional variations, and a characteristic immunohistochemical

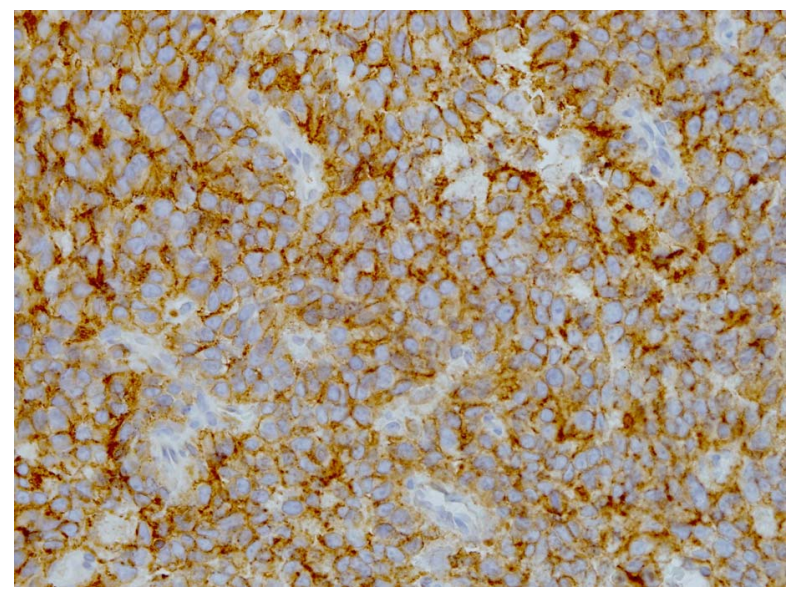

Figure 4 Immunohistochemistry CD99 positive. staining profile. Both tumours show different degrees of neuroectodermal differentiation; Ewing's sarcoma tends to be poorly differentiated, whereas PNET most often shows definite neuroectodermal differentiation. ${ }^{3}$ Although once viewed as distinct entities, Ewing's sarcoma, Askin's tumour (arising from chest wall) and PNET are now considered together as members of the Ewing's family of tumours. As such, they are increasingly grouped together for both treatment and prognostic factor analysis. $^{4}$

Extensive literature search revealed very few cases of primary Ewing's sarcoma/PNET of breast reported..$^{5-9}$ There is also a case reported as Ewing's sarcoma of bone metastasising to breast. ${ }^{2}$ Until now, there are no data specific to primary Ewing's sarcoma/PNET of breast, in regards to risk factors, prognosis and survival rates. Such information is based on data derived from studies on extraskeletal Ewing's sarcoma/PNET as a whole. Baldini et al studied various prognostic factors of adult primary extraosseous (extraskeletal) Ewing's sarcoma/PNET. They identified three factors associated with poor prognosis: primary extraosseous tumour, age more than 26 years at presentation and metastatic disease at presentation. ${ }^{3}$ Overall the survival rate for 5 years was $38 \%$ whereas 5 year survival rate for localised disease was $49 \%$. $^{3}$

Several case reports on primary breast Ewing's sarcoma/PNET showed that patients are mainly young adults in their early $30 \mathrm{~s},{ }^{5-8}$ as in the case of our patient. However, Popli et al reported a 14-year-old girl with unilateral localised primary Ewing's sarcoma, which to the best of our knowledge, is the youngest reported so far. ${ }^{9}$ Presentation varies between reports. deSilva $\mathrm{et}_{\mathrm{al}}^{7}$ reported a 35-year-old womanpresented with inoperable large tumour, where as Maxwell et $a l^{5}$ and Kim et $a l^{8}$ reported small cystic lesions which appeared benign. Most cases presented $\mathrm{w}$ solid and well-circumscribed breast lumps. ${ }^{2} 679$ Most cases reported diagnosis obtained by tissue incisional biopsy or core-needle biopsy. ${ }^{6-9}$ Fine needle aspiration cytology (FNAC) for initial assessment was reported by Popli et al where small round blue cells were identified on cytology smear. However, histopathological examination of tissue with immunohistochemical staining is still required to achieve definite diagnosis. ${ }^{9}$ This case was diagnosed by core needle biopsy, using trucut needle size $18 \mathrm{Fr}$, performed on both sides.

Histologically, these tumours consist of small cells with round nuclei and little rim of cytoplasm. They belong to a heterogenous group of malignant small round cell tumours that includes neuroblastoma, embryonal rhabdomyosarcoma and lymphoma. ${ }^{3}$

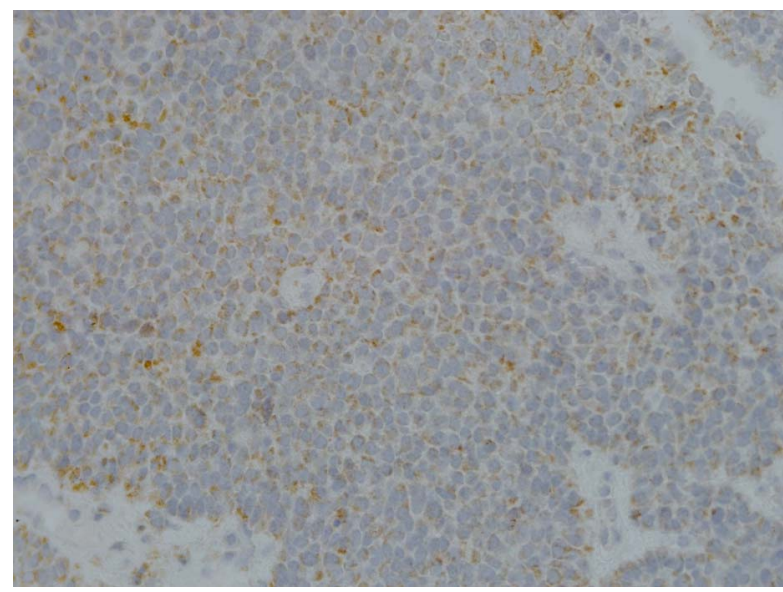

Figure 5 Immunohistochemistry-chromogranin A positive. 
Ewing sarcoma/PNET is distinguished by immunohistochemical analysis, where CD99 positivity is considered confirmatory for this diagnosis (figure 5). ${ }^{3}$ CD99 is a cell surface glycoprotein involved in cell adhesion. ${ }^{6}$ Reactivity to vimentin, synaptophysin, neuron-specific enolase (NSE) and S-100 may suggest diagnosis but are not confirmatory. ${ }^{7}$ In this case, immunohistochemistry tested positive for CD99, vimentin and synaptophysin.

Various imaging modalities have been reported but none have shown specific appearance pertaining to this group of tumour. Mammogram use was reported in Ko et $a l^{6}$ and Kim et $a l^{8}$ where both described dense breast tissue without any microcalcification. Simple radiography reveals only non-specific soft tissue mass. ${ }^{8}$ Mammogram was not performed in this patient for two reasons; the patient is less than 35 years, therefore mammography image is less sensitive in picking up breast lesion in patients with dense breast tissue. Furthermore, this patient presented with painfully large breast tumour with skin oedema and ulceration, hence mammography unsuitable for her. Ultrasound appearances were reported as non-specific hypoechoic, well-circumscribed lesion with posterior acoustic enhancement in several reports. ${ }^{58}$ Maxwell et $a l^{5}$ described a similar lesion with an apparent hypoechoic tract extending to the skin, which was initially misdiagnosed as a benign epidermal inclusion cyst. We did not request for sonographic study for this patient.

High resolution CT scan and MRI are useful in aiding diagnosis and surgical planning, although there are no specific features for this group of tumours. ${ }^{8}$ They usually appear as large, noncalcified, soft tissue masses with a heterogeneous appearance and cystic or necrotic areas on $\mathrm{CT}^{6}$ By MRI, signal intensity was similar to muscle on T1-weighted images and heterogeneously high on T2-weighted images, with variable gadolinium enhancement. Bright, heterogeneously high signal intensity on T2-weighted images is caused by focal areas of haemorrhage or necrosis. ${ }^{6}$ In this case, CT scan was used to assess the extent of tumour infiltration, at the same time assess for distant metastasis to regional lymph nodes, bone, lungs and liver. It also enables assessment of the axial skeleton and chest wall which are the more common sites of Ewing's sarcoma. Positron emission tomography (PET) and bone scintigraphy were suggested by Koet $a l^{6}$ and Kim et $a l^{8}$ as a useful whole body screen for other foci of osseous and extraosseous tumours.

Management varies according to the presentation and experience of each centre as there are no established guidelines on primary Ewing's sarcoma/PNET of the breast. The guiding principles are derived from treatment approach and chemotherapy regimens targeted on soft tissue sarcomas. ${ }^{10}$ In localised soft tissue sarcoma in adult, surgery is the standard treatment with wide excision to achieve negative margins. In primary breast sarcomas, breast conserving surgery is feasible along with postoperative radiotherapy. Axillary clearance is unnecessary. ${ }^{10}$ It is recommended by ESMO guideline that safe surgical margins should be at least $1 \mathrm{~cm}^{10}$ Ko et al ${ }^{6}$ and Manju et al ${ }^{9}$ reported patients with relatively small and localised tumours, treated with wide excision of the affected breasts only with good results. Generally, with regard to soft tissue sarcoma, external beam irradiation after wide excision is advocated for high-grade lesion of more than $5 \mathrm{~cm}$ size as it has been shown to improve local control. However, in conditions where there is a lack of consensus across reference centres, such as our case, smaller tumours have too been treated with adjuvant radiotherapy after a multidisciplinary discussion involving the oncologist, pathologist and surgeons. ${ }^{10}$ Post wide excision chemotherapy improves, or at least delays, distant and local recurrence in high-risk patients, and it is shown that combination regimen is beneficial for patients presented with advanced disease. However, no significant data showing adjuvant chemotherapy prolonging overall and relapse-free survival. ${ }^{10}$ In Kim et $a l,{ }^{8}$ the patient presented with a localised lesion, and was subjected to mastectomy and adjuvant chemotherapy with vincristine, adriamycin and cyclophosphamide. Alkylating agents and anthracyclines are recommended as first-line therapy. ${ }^{10}$ In cases of inoperable tumours or patients presented with distant metastasis, chemotherapy is the first-line treatment, as in our case. ${ }^{7} 10$ de Silva et al reported a case of primary inoperable breast PNET responded to chemotherapy consist of cisplatin, etoposide and doxorubicin, followed by radiotherapy, achieving disease-free survival of 2 years. ${ }^{7}$ In our case, patient received vincristine, adriamycin and cyclophosphamide. Unfortunately, the patient presented with lung metastasis and her condition further deteriorated after chemotherapy.

\section{Learning points}

- Despite its rarity, Ewing's sarcoma/primitive neuroectodermal tumour (PNET)has been reported to arise primarily from breast tissue. High index of suspicion is advisable when dealing with young women with rapidly enlarging breast lumps.

- There is no consensus or guidelines of management specific for primary breast Ewing's sarcoma/PNET.

- Most of the literature recommended removal of the tumour as definitive treatment. However, in cases of inoperable tumours or metastatic disease, as in our case, systemic multiagent chemotherapy prior to surgery with adjunct external beam irradiation is an option.

Contributors SMI wrote the manuscript. VKTK was involved in writing the case report. AS edited the pathology photographs and AAMZ was involved in writing the pathology discussion part.

Competing interests None.

\section{Patient consent Obtained.}

Provenance and peer review Not commissioned; externally peer reviewed.

\section{REFERENCES}

1 Angerwall L, Enzinger FM. Extraskeletal neoplasms resembling Ewing's sarcoma. Cancer 1975;36:240-51.

2 Örgüç S, Başara I, Poçan T, et al. Ewing's sarcoma metastasis into the breast. Diagn Interv Radiol 2012;18:167-70.

3 Baldini EH, Demetri GD, Fletcher CDM, et al. Adults with Ewing's sarcoma/ primitive: neuroectodermal tumor adverse effect of older age and primary extraosseous disease on outcome. Ann Surg 1999;230:79-86.

4 Bruckner JD, Conrad EU, Malo L. Primitive neuroectodermal tumor and extraosseous Ewing's sarcoma: a comparison of clinical features and management. Proc Am SoC Clin Oncol 1992;11:414.

5 Maxwell RW, Ghate SV, Bentley RC, et al. Primary primitive neuroectodermal tumor of the breast. J Ultrasound Med 2006;25:1331-3.

6 Ko K, Kim EA, Lee ES, et al. Primary primitive neuroectodermal tumor of the breast: a case report. Korean J Radiol 2009;10:407-10.

7 Da Silva BB, Lopes-Costa PV, Pires CG, et al. Primitive neuroectodermal tumor of the breast. Eur J Obstet Gynecol Reprod Biol 2008;137:248-9.

8 Kim YS, Lee KH, Choi SJ, et al. Extraskeletal Ewing's sarcoma of the breast, mimicking cyst. J Korean Surg Soc 2010;79:411-14.

9 Popli MB, Popli V, Bahl P, et al. Extraskeletal Ewing's sarcoma of the breast. Eur J Radio/2009;70e65-6.

10 Casali PG, Blay JY. Clinical Practice Guidelines: soft tissue sarcoma: ESMO Clinical Practice Guidelines for diagnosis, treatment and follow-up. Ann Oncol 2010;21: v196-203. 
Copyright 2013 BMJ Publishing Group. All rights reserved. For permission to reuse any of this content visit http://group.bmj.com/group/rights-licensing/permissions.

BMJ Case Report Fellows may re-use this article for personal use and teaching without any further permission.

Become a Fellow of BMJ Case Reports today and you can:

- Submit as many cases as you like

- Enjoy fast sympathetic peer review and rapid publication of accepted articles

- Access all the published articles

- Re-use any of the published material for personal use and teaching without further permission

For information on Institutional Fellowships contact consortiasales@bmjgroup.com

Visit casereports.bmj.com for more articles like this and to become a Fellow 